\title{
Balloon-Guided Endoscopic Procedure
}

National Cancer Institute

\section{Source}

National Cancer Institute. Balloon-Guided Endoscopic Procedure. NCI Thesaurus. Code C64865.

An endoscopic technique that allows deep intubation of the small intestine while using a standard endoscope. An inflatable balloon attached to the endoscope's tip acts as a stabilizer and a second balloon that is advanced ahead of the endoscope acts as a pulling device. 